\title{
DEFINITION AND CALCULATION OF OBJECTIVE FUNCTIONS OF ARTILLERY WEAPONRY
}

\author{
Stelian POPESCU \\ “Nicolae Bălcescu” Land Forces Academy, Sibiu, Romania \\ fam_popes@yahoo.com
}

\begin{abstract}
The technical resource of artillery weaponry can be highlighted, in an original way, with the help of functions, called objective functions by the author. In this respect, an original mathematical model thereof was defined and is presented, detailing the main and secondary subassemblies, and the general assembly of a mouth, respectively. The developed model connects subassemblies and the product through the weights given to each component within the system, the defining element from which it starts being the diagnosis parameters.
\end{abstract}

Key words: objective function, mathematical model, diagnosis parameters, artillery weaponry

\section{Introduction}

Determining the objective function of a mouth can be performed only after having previously drafted the diagnosis tree by means of which component subassemblies and their hierarchical levels were established. Consistent with the diagnosis tree, the technical condition diagnosis sheet is drawn up, comprising main and secondary subassemblies levels I, II and III. The tree structure of the technical condition diagnosis sheet for artillery weaponry allows the definition and calculation of objective functions for main and secondary subassemblies, as well as for the general assembly.

\section{Objective Functions for Secondary Level III Subassemblies}

These functions are determined starting from the diagnosis sheets of secondary level III subassemblies, where information concerning the scores awarded to diagnosis parameters and the weight that parameters have in the diagnosis process of each subassembly is taken from.
Objective functions for level III secondary subassemblies, $\mathrm{F}_{\mathrm{ob} j} \mathrm{III}$, are calculated using the mathematical relation (1):

$\mathrm{F}_{\text {ob } \mathrm{j}}^{\mathrm{III}}=\sum_{\mathrm{i}=1}^{\mathrm{n}} \mathrm{w}_{\mathrm{qlkji}} \cdot \mathrm{p}_{\mathrm{qlkji}}$

where:

$\mathrm{w}_{\mathrm{qlkji}}$ - the weight given to the iparameter within the process of diagnosis of the level III secondary subassembly analyzed $(0<$ $\left.\mathrm{w}_{\mathrm{qlkji}} \leq 1\right)$;

$\mathrm{p}_{\mathrm{qlkji}}$ - the score awarded to the iparameter within the diagnosis process according to the diagnosis sheet of the level III secondary subassembly under analysis $\left(\mathrm{p}_{\mathrm{qlkji}}=\{1,2,3\}\right)$. $\mathrm{p}_{\mathrm{qlkji}}=1$, when the evaluated parameter has the measured value corresponding to the nominal value; 
$\mathrm{p}_{\mathrm{qlkji}}=2$, when the evaluated parameter has the measured value corresponding to the admissible value;

$\mathrm{p}_{\mathrm{qlkji}}=3$, when the evaluated parameter has the measured value corresponding to the critical value.

$\mathbf{i}$ - the index by means of which we index the number of parameters within the diagnosis sheet $(i=\overline{1, n})$;

$\mathbf{n}$ - the number of parameters taken into account within the process of diagnosis according to the diagnosis sheet of the level III secondary subassembly under analysis.

For each level III secondary subassembly considered (examined) condition (2) must be observed:

$\sum_{\mathrm{i}=1}^{\mathrm{n}} \mathrm{w}_{\text {qlkji }}=1$

At this level, for each subassembly analyzed diagnosis sheets will be drafted based on the weights and scores given to each parameter in question.

\section{Objective Functions for Level II} Secondary Subassemblies

Objective functions for level II subassemblies are determined by means of the objective functions for level III secondary subassemblies and the weight given to these subassemblies in the process of diagnosis of level II secondary subassemblies.

Objective functions for level II subassemblies, $\mathrm{F}_{\text {obk }}^{\mathrm{II}}$, are calculated using the mathematical relation(3)

$\mathrm{F}_{\mathrm{obk}}^{\mathrm{II}}=\sum_{\mathrm{j}=1}^{\mathrm{m}} \mathrm{w}_{\mathrm{qlkj}}^{\mathrm{III}} \cdot \mathrm{Fob}_{\mathrm{j}}^{\mathrm{III}}$

where:

$\mathrm{w}_{\mathrm{qlkj}}^{\mathrm{III}}$ - the weight given to the level III secondary subassembly within the process of diagnosis and calculus of the objective function for the level II secondary subassembly that it is part of $\left(0<\mathrm{w}_{\mathrm{qlkj}}^{\mathrm{III}} \leq 1\right)$; j - the index by which we index the number of level III secondary subassemblies within the level II secondary subassembly $(\mathrm{j}=\overline{1, \mathrm{~m}})$;

m - the number of level III secondary subassemblies within the level II secondary subassembly under analysis.

For each level II secondary subassembly considered condition (4) must be observed:

$\sum_{\mathrm{j}=1}^{\mathrm{m}} \mathrm{W}_{\mathrm{qlkj}}^{\mathrm{III}}=1$

\section{Objective Functions for Level I Secondary Subassemblies}

Objective functions for level I subassemblies are determined by means of the objective functions for level II secondary subassemblies and the weight given to these subassemblies in the process of diagnosis of level I secondary subassemblies.

Objective functions for level I secondary subassemblies, $\mathrm{F}_{\text {obl }}^{\mathrm{I}}$, are calculated using the mathematical relation (5)

$\mathrm{F}_{\mathrm{obl}}{ }_{\mathrm{I}}^{\mathrm{I}}=\sum_{\mathrm{k}=1}^{\mathrm{t}} \mathrm{w}_{\mathrm{qlk}}^{\mathrm{II}} \cdot \mathrm{F}_{\mathrm{obk}}{ }_{\mathrm{II}}^{\mathrm{II}}$

where:

$\mathrm{w}_{\mathrm{qlk}}^{\mathrm{II}}$ - the weight given to the level II secondary subassembly within the process of diagnosis and calculus of the objective function for the level I secondary subassembly that it is part of $\left(0<\mathrm{w}_{\mathrm{qlk}}^{\mathrm{II}} \leq 1\right)$;

$\mathbf{k}$ - the index by which we index the number of level II secondary subassemblies within the level I secondary subassembly $(\mathrm{k}=\overline{1, \mathrm{t}})$;

$\mathbf{t}$ - the number of level II secondary subassemblies within the level I secondary subassembly under analysis.

For each level I secondary subassembly considered condition (6) must be observed:

$\sum_{\mathrm{k}=1}^{\mathrm{t}} \mathrm{W}_{\mathrm{qlk}}^{\mathrm{II}}=1$

5. Objective Functions for Primary Subassemblies 
These are determined by means of the objective functions for level I secondary subassemblies and the weight given to these subassemblies in the process of diagnosis of main subassemblies.

Objective functions for main subassemblies, $\mathrm{F}_{\mathrm{obq}}^{\mathrm{p}}$, are calculated using the mathematical relation(7)

$$
\mathrm{F}_{\mathrm{ob} \mathrm{q}}^{\mathrm{p}}=\sum_{\mathrm{l}=1}^{\mathrm{v}} \mathrm{w}_{\mathrm{ql}}^{\mathrm{I}} \cdot \mathrm{F}_{\mathrm{ob} 1}^{\mathrm{I}}
$$

where:

$\mathrm{w}_{\mathrm{ql}}^{\mathrm{I}}$ - the weight given to the level I secondary subassembly within the process of diagnosis and calculus of the objective function for the main subassembly that it is part of $\left(0<\mathrm{w}_{\mathrm{ql}} \leq 1\right)$;

l - the index by which we index the number of level I secondary subassemblies within the main subassembly that it is part of $(1=\overline{1, v})$;

$\mathbf{v}$ - the number of level I secondary subassemblies within the main subassembly that it is part of.

For each main subassembly considered condition (8) must be observed:

$$
\sum_{\mathrm{l}=1}^{\mathrm{v}} \mathrm{w}_{\mathrm{ql}}^{\mathrm{I}}=1
$$

\section{The Objective Function of the Mouth}

The objective function of the mouth offers information on the classification of mouths in the artillery park on categories of technical state and making decisions on whether or not to maintain them operational. Finally, using the graph of objective function variation, we will determine the remaining resource of the mouth until reaching the critical values of the parameters considered, those making the mouth no longer viable to be maintained in operation.

The objective function of the mouth is determined with the help of objective functions for main subassemblies and the weight awarded to them within the diagnosis process of the mouth.

The objective function of the mouth, $\mathrm{F}_{\mathrm{ob}}$ gf , is calculated using the mathematical relation(9)

$\mathrm{F}_{\mathrm{ob}}{ }^{\mathrm{gf}}=\sum_{\mathrm{q}=1}^{\mathrm{s}} \mathrm{w}_{\mathrm{q}}^{\mathrm{p}} \cdot \mathrm{F}_{\mathrm{ob}}^{\mathrm{p}}$

where:

$\mathrm{w}_{\mathrm{q}}^{\mathrm{p}}$ - the weight given to the $\mathrm{q}$ main subassembly within the process of diagnosis and calculus of the objective function of the mouth $\left(0<\mathrm{w}_{\mathrm{q}}^{\mathrm{p}} \leq 1\right)$;

$\mathrm{q}$ - the index by which we index the number of main subassemblies of the $\operatorname{mouth}(\mathrm{q}=\overline{1, \mathrm{~s}})$;

$\mathrm{s}-$ the number of main subassemblies of the mouth.

For the mouth considered condition (10) must be observed:

$\sum_{\mathrm{q}=1}^{\mathrm{s}} \mathrm{w}_{\mathrm{q}}^{\mathrm{p}}=1$

Considering how objective functions were defined for main and secondary subassemblies, levels I, II and III, according to the relations (1), (3), (5) and (7), the objective function of the mouth can be calculated directly using relation (11):

$\mathrm{F}_{\mathrm{ob}}^{\mathrm{qf}}=\sum_{\mathrm{q}=1}^{\mathrm{s}} \mathrm{w}_{\mathrm{q}}^{\mathrm{p}}\left[\sum_{\mathrm{l}=1}^{\mathrm{v}} \mathrm{w}_{\mathrm{ql}}^{\mathrm{I}}\left[\sum_{\mathrm{k}=1}^{\mathrm{t}} \mathrm{w}_{\mathrm{qlk}}^{\mathrm{II}}\left[\sum_{\mathrm{j}=1}^{\mathrm{m}} \mathrm{w}_{\mathrm{qlkj}}^{\mathrm{III}}\left[\sum_{\mathrm{i}=1}^{\mathrm{n}} \mathrm{w}_{\mathrm{qlkji}} \cdot \mathrm{p}_{\mathrm{qlkji}}\right]\right]\right]\right]$

\section{Conclusions}

Diagnosing the technical state of medium and large caliber artillery weapons provides information on the classification of mouths in the artillery park in relation to their objective function values.

The value of the mouth's objective function, at a specific time, provides us with information about its technical 
resource, corresponding to the value of the function. Therefore, it can be appreciated the moment when the mouth reaches critical values, which make its operation unsafe or dangerous in terms of the security of the personnel operating it.

The objective functions of the main and secondary subassemblies, as well as that of the mouth were calculated and defined in an original manner, the mathematical apparatus used being an accessible one for the personnel having an average level of training.

The evolution (variation) in time of objective functions for artillery mouths will be analyzed in relation to the laws of variation considered, the values obtained being accurate in establishing the technical resources of the weaponry until reaching the critical values of the parameters considered.

\section{References}

[1] Bezovsky, I., Fiabilite - theorieetpratique de la surete de fonctionnement, Dunod Publishing House, Paris, 1966.

[2] Constantin, Gh., Nuţu, V, Basics of Weapons Systems Reliability, A.T.M. Publishing House, Bucharest 1996.

[3] Manea, C.; Stratulat, M., Reliability and Diagnosis of Vehicles, The Military Publishing House, Bucharest, 1982.

[4] Popescu, St.; Dascălu, V., Calculus of System Reliability, Scientific Conference, "Nicolae Bălcescu" Land Forces Academy, Sibiu, 2002.

[5] Popescu, St.; Dascălu, V., Risk Management in Maintaining Artillery Weaponry, Scientific Conference, "Nicolae Bălcescu” Land Forces Academy, Sibiu, 2005. 